\title{
Model Tests on the Retaining Walls Constructed from Geobags Filled with Construction Waste
}

\author{
Hua Wen, Jiu-jiang Wu, Jiao-li Zou, Xin Luo, Min Zhang, and Chengzhuang Gu \\ School of Civil Engineering and Architecture, Southwest University of Science and Technology, Mianyang 621010, China \\ Correspondence should be addressed to Hua Wen; 47702099@qq.com
}

Received 22 January 2016; Revised 21 June 2016; Accepted 22 June 2016

Academic Editor: Luigi Nicolais

Copyright ( 2016 Hua Wen et al. This is an open access article distributed under the Creative Commons Attribution License, which permits unrestricted use, distribution, and reproduction in any medium, provided the original work is properly cited.

Geobag retaining wall using construction waste is a new flexible supporting structure, and the usage of construction waste to fill geobags can facilitate the construction recycling. In this paper, model tests were performed on geobag retaining wall using construction waste. The investigation was concentrated on the slope top settlement, the distribution characteristics of the earth pressures on retaining walls and horizontal wall displacements, and slope failure modes. The results indicated that the ultimate loads that the slope tops with retaining walls could bear were $87.5 \% \sim 125 \%$ higher than that of the slope top without retaining walls. The ultimate loading of strengthened slopes with different slope ratios from $1: 0.75$ to $1: 0.25$ could be reduced by $11.8 \%$ to $29.4 \%$. The horizontal displacements of the retaining walls constructed from geobags were distributed in a drum shape, with the greatest horizontal displacements occurring about 1/3 1/2 of the wall height away from the bottom of the wall. As the slope ratio increased, the failure of the slope soil supported by geobag retaining wall using construction waste changed from sliding to sliding-toppling (dominated by sliding) and then to toppling-sliding (dominated by toppling). The range of 1/3 1/2 of wall height is the weak part of the retaining walls, which should be strengthened with certain measures during the process of design and construction.

\section{Introduction}

A significant part of waste generation is caused by the building and construction industry. This includes building materials such as insulation, nails, electrical wiring, and rebar, as well as waste generated from site preparation such as dredging materials, tree stumps, and rubble [1]. Waste concrete and waste bricks are the primary components of construction waste, the recycling of which has always been an important area studied by domestic and foreign scholars. Waste concrete and waste bricks are referred to as construction waste in this paper.

Geobags are often filled with construction waste to construct gravity retaining walls in order to support slopes. The retaining walls constructed from geobags filled with construction waste are a new flexible supporting structure characterized by easy construction, low costs, and good supporting effects and facilitate the recycling of construction waste [2]. Geobags were used as early as in ancient Egypt and then were applied to water conservancy projects, subgrade engineering, and treatment of soft soil [3]. The amazing bearing capacity of geobags has, however, inspired the development of an earth reinforcement method in which the bearing capacity of soft foundations is enhanced $[4,5]$. Geobag technology has been applied in many engineering fields and the relevant studies including model tests $[6,7]$ and numerical analyses $[8,9]$ have been conducted. However, there are currently only some projects of retaining walls constructed from geobags, and there is a lack of systematic studies on them. Meanwhile, the materials used to fill geobags are normally sand and rubble $[10,11]$.

In recent years, domestic and foreign scholars have conducted extensive studies on construction waste, which have primarily been focused on the applications of waste concrete as recycled aggregate to reinforced concrete structures [12] and roads [13]. However, there have been no reports of studies on the applications of construction waste to retaining walls constructed from geobags.

In this study, waste concrete, a principal component of construction waste, was used as the material to fill geobags to conduct laboratory model tests on the slope with no support and slopes with different slope ratios supported by 


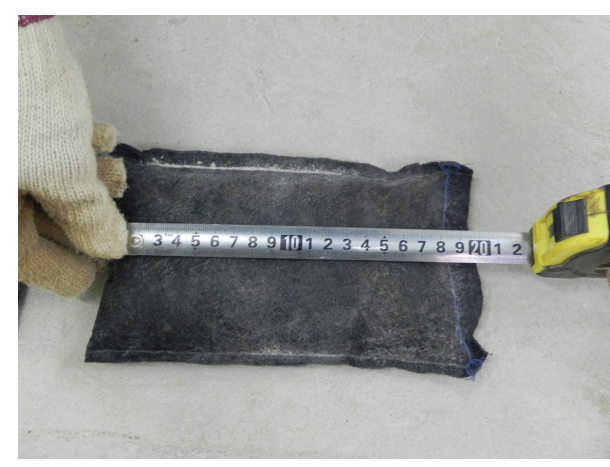

(a)

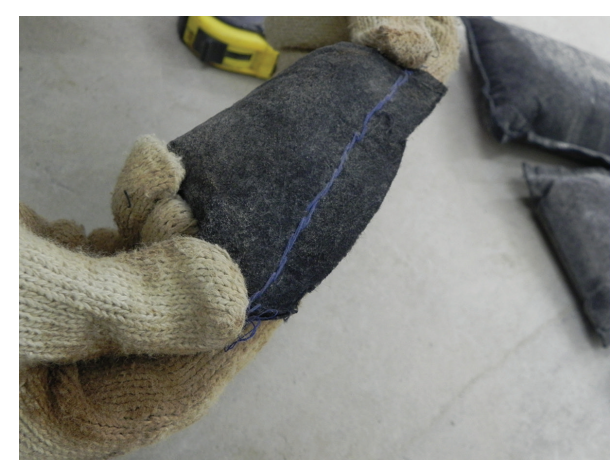

(b)

FIGURE 1: Geobag used in the model tests. (a) Measuring the size of geobag; (b) sewing up the geobag.

TABLE 1: Physical and mechanical properties of slope soil.

\begin{tabular}{lccc}
\hline $\begin{array}{l}\text { Density } \\
\left(\mathrm{g} / \mathrm{cm}^{3}\right)\end{array}$ & $\begin{array}{c}\text { Moisture } \\
\text { content }(\%)\end{array}$ & $\begin{array}{c}\text { Cohesion } \\
(\mathrm{kPa})\end{array}$ & $\begin{array}{c}\text { Internal friction } \\
\text { angle }\left({ }^{\circ}\right)\end{array}$ \\
\hline 1.7 & 15.3 & 26.9 & 25.9 \\
\hline
\end{tabular}

the retaining walls with different widths constructed from geobags filled with construction waste in order to study the relationship between the vertical settlement of the slope top and the load applied to the slope top, the distribution characteristics of the horizontal displacements of the retaining wall and the earth pressures on the retaining wall, and the failure modes of the slopes, in different cases. The results are expected to provide bases for the design and construction of retaining walls constructed from geobags filled with construction waste.

\section{Model Design and Preparation}

The laboratory model tests were based on the principle of similarity theory and dimensional analysis. Prototype slopes with slop ratios of $1: 0.25,1: 0.5$, and $1: 0.75$ under the same height of $6 \mathrm{~m}$ were selected. The similarity ratios of geometry, load, stress, and soil inner frictional angle for the model slopes to the prototype slopes were determined to be $1: 4$, $1: 16,1: 16$, and $1: 1$, respectively. Since gravity and soil cohesion cannot satisfy the similarity ratio strictly, the obtained data of model slopes could not be applied directly to the prototype slopes. Therefore, the model tests in this study can be treated as a "small-scale test [14]". Although model tests may not be similar to the reality, some regular conclusions can be drawn through qualitative research and contribute to studies on actual projects.

\subsection{Experimental Materials}

2.1.1. Rock Mass Material. The common silty clay in Sichuan Province was used as the slope soil, whose physical and mechanical parameters were determined by geotechnical tests according to the Specification of Soil Test (S1237-1999) [15]. The physical and mechanical parameters of the slope soil are shown in Table 1.

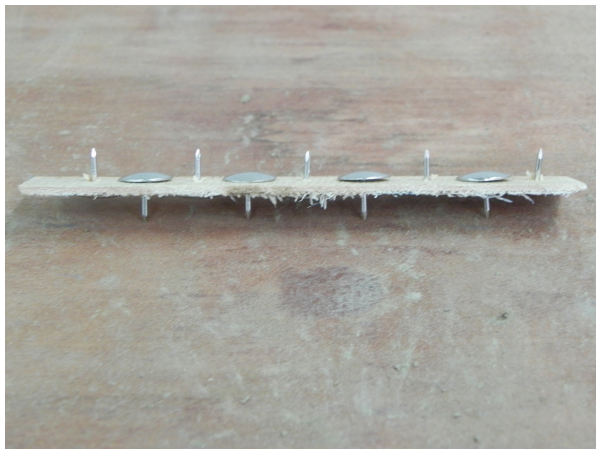

Figure 2: Connector used in the model tests.

2.1.2. Material Used to Fill Geobags. Waste concrete aggregate was used to fill the geobags. The particle sizes of the prototype waste concrete crushed using a jaw crusher that offered a maximum particle size of $20 \mathrm{~mm}$ were scaled at a geometric similarity ratio of $1: 4$. The contents of the scaled particle sizes remained unchanged. The physical and mechanical parameters of the waste concrete aggregate after particle size scaling are shown in Tables 2 and 3.

2.1.3. Geobags and Connectors. The dimensions of the prototype and model geobags were $440 \mathrm{~mm} \times 815 \mathrm{~mm}$ and $110 \mathrm{~mm} \times 204 \mathrm{~mm}$, respectively, and the geobags were $80 \%$ filled, as shown in Figure 1. Connectors were produced by the manufacturer and could not be scaled. Therefore, thin pieces of wood and pushpins were used to replace the model connectors. The pushpins were pressed into the wood. The dimensions of the prototype and model connectors were $320 \mathrm{~mm} \times 120 \mathrm{~mm} \times 56 \mathrm{~mm}$ and $80 \mathrm{~mm} \times 30 \mathrm{~mm} \times 14 \mathrm{~mm}$, respectively, as shown in Figure 2.

Physical tests were performed on the model waste concrete aggregate, and mechanical tests were performed on the model waste concrete aggregate in bags with and without the model connectors to determine the friction coefficient between the model waste concrete aggregate and model geobags and the friction coefficients between geobags with and without connectors, which were then compared with the physical and mechanical indicators of the prototype waste 
TABLE 2: Gradation of the waste concrete aggregate before and after its particle size scaling.

\begin{tabular}{|c|c|c|c|c|c|c|c|c|c|}
\hline Particle sizes before scaling/mm & 20 & 19 & 16 & 9.5 & 4.75 & 2.36 & 1.18 & 0.6 & 0.3 \\
\hline Particle sizes after scaling/mm & 5 & 4.75 & 4 & 2.36 & 1.18 & 0.6 & 0.3 & 0.15 & 0.075 \\
\hline Percentage of particles smaller than the particle size/\% & 100 & 86.2 & 71.2 & 34.1 & 14.0 & 6.4 & 3.77 & 2.73 & 1.63 \\
\hline
\end{tabular}

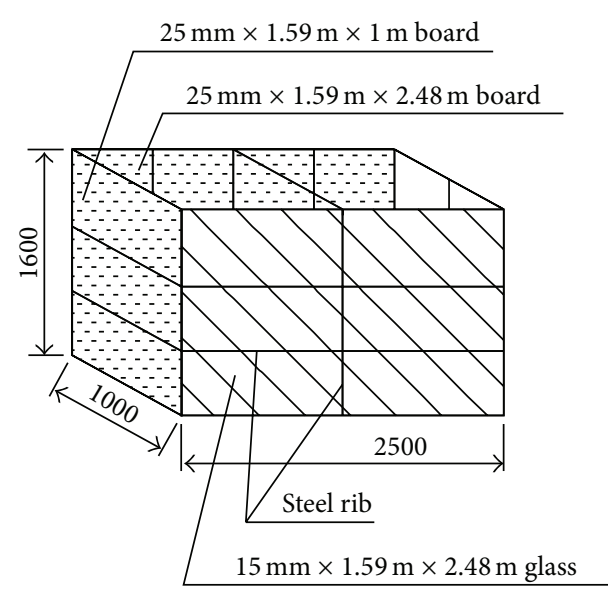

(a)

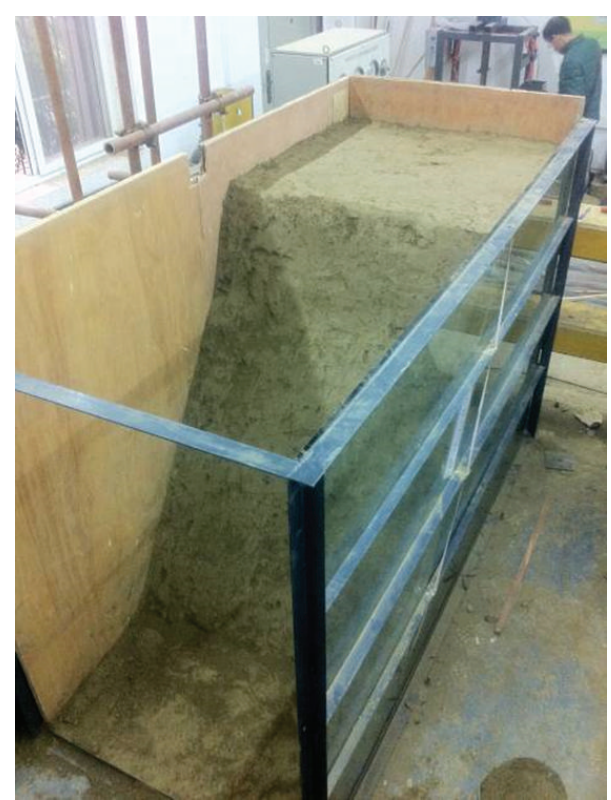

(b)

Figure 3: Test tank. (a) Schematic diagram of the test tank (unit: mm). (b) Top view of the test tank.

concrete aggregate, as shown in Table 3. In it, $c^{\prime}$ is soil cohesion and $\varphi^{\prime}$ refers to soil inner frictional angle. According to Table 3, the interfacial shear strength between the geobags filled with construction waste in the model tests was smaller than that between the prototypes filled with construction waste.

2.2. Test Tank Design. The tank with a size of $2.5 \mathrm{~m} \times 1 \mathrm{~m} \times$ $1.6 \mathrm{~m}$ was welded with $50 \times 50 \times 5$ steel angles. Every surface of the tank was ribbed with the same type of steel angles, as shown in Figure 3 (dimensions not marked with a unit were all measured in $\mathrm{mm}$ ).

A movable rib was placed in the middle of the top surface and at the top of the left surface, respectively. The movable ribs were removed when a slope was built. After that, the movable ribs were replaced in order to prevent the tank from moving when a load was applied to the top of the slope. Two sides of the tank were supported by a $25 \mathrm{~mm}$ thick board, and another side was supported by a $15 \mathrm{~mm}$ thick piece of tempered glass for clear observation, as shown in Figure 3.

2.3. Model Design. Laboratory tests were performed in the following five cases: a slope with a slope ratio of $1: 0.5$ without reinforcement (Q1), a slope with a slope ratio of $1: 0.5$ supported by a $370 \mathrm{~mm}$ wide retaining wall (Q2), a slope with a slope ratio of $1: 0.5$ supported by a $570 \mathrm{~mm}$ wide retaining wall (Q3), a slope with a slope ratio of $1: 0.25$ supported by a $370 \mathrm{~mm}$ wide retaining wall (Q4), and a slope with a slope ratio of 1:0.75 supported by a $370 \mathrm{~mm}$ wide retaining wall (Q5). The schematic diagrams of the model slopes are shown in Figure 4. The slopes were all $1.5 \mathrm{~m}$ high.

2.4. Layout of Instruments. Twelve earth pressure cells were placed in the area where the slope and the retaining wall were in contact to measure the horizontal earth pressures acting on the retaining wall. Two dial indicators were placed at the top of the slope to measure its settlement. Two rows of dial indicators (six dial indicators in each row) were distributed over the wall height to measure the horizontal displacements of the retaining wall.

The measuring instruments were placed as shown in Figure 5. Two measuring instruments were placed at the same height, and the average values of their measured data were used as the final result.

2.5. Loading Device. A uniform load was applied by a steel plate with a size of $1 \mathrm{~m} \times 1 \mathrm{~m} \times 12 \mathrm{~mm}$ (length $\times$ width $\times$ thickness) on the top of each slope. Graduated compression was applied to the top of each slope by a hydraulic jack until the steel plate carried a uniformly distributed load. The next level of loading was not activated until the readings on the earth pressure cells and dial indicators remained constant. The uniform load applied to the top of each slope was treated as the failure load when the amount of settlement of the slope top increased rapidly (the amount of settlement caused by the applied uniform load was greater than twice the amount 


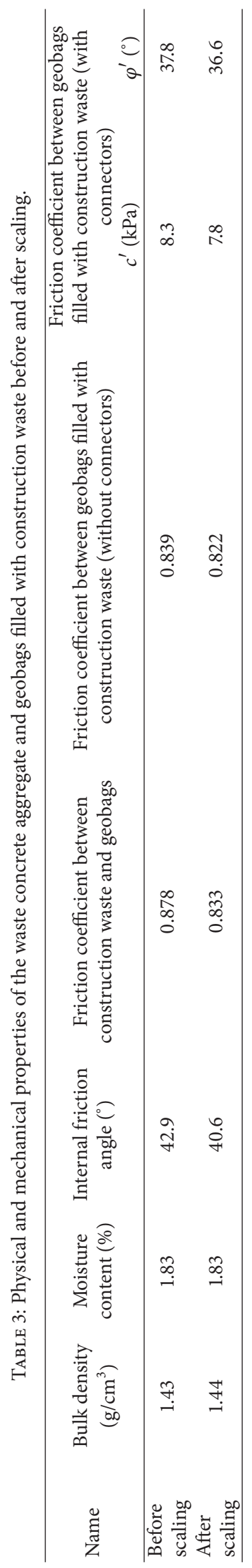




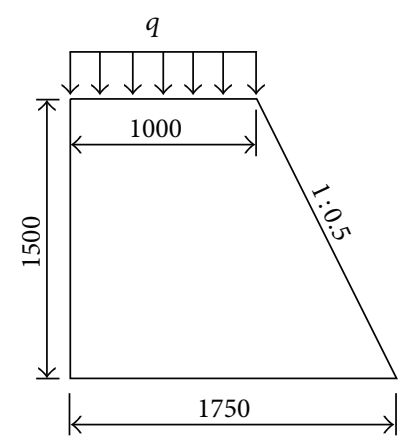

(a)

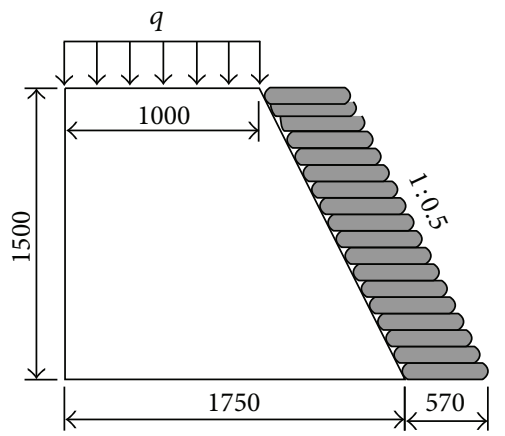

(c)

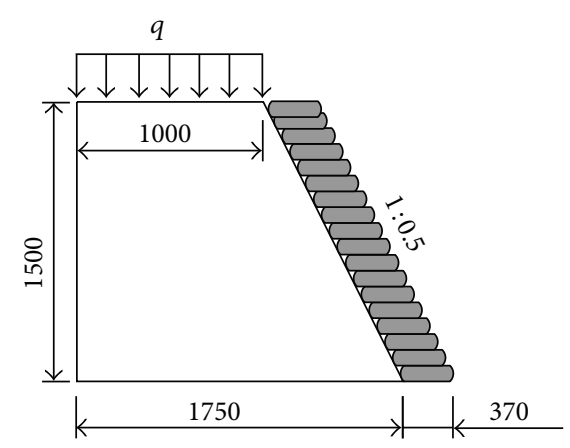

(b)

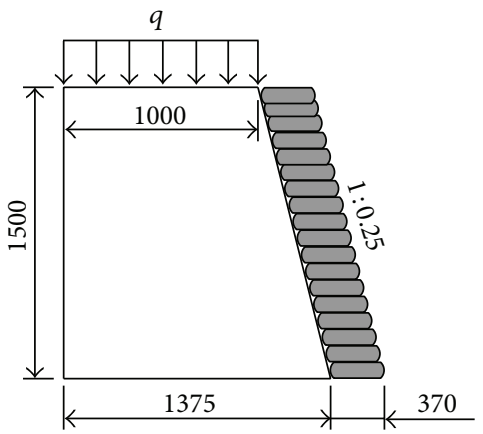

(d)

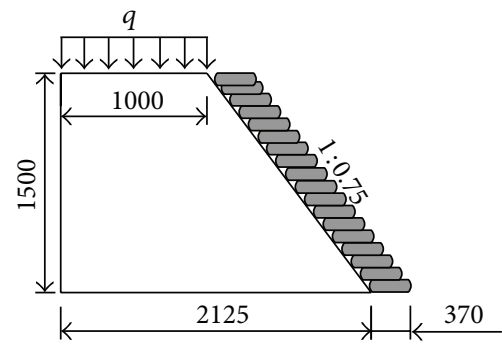

(e)

Figure 4: Model slopes (unit: $\mathrm{mm}$ ). (a) Q1: slope with a slope ratio 1:0.5. (b) Q2: slope with a slope ratio of 1:0.5 supported by a $370 \mathrm{~mm}$ wide geobag retaining wall. (c) Q3: slope with a slope ratio of 1:0.5 supported by a $570 \mathrm{~mm}$ wide geobag retaining wall. (d) Q4: slope with a slope ratio of 1:0.25 supported by a $370 \mathrm{~mm}$ wide geobag retaining wall. (e) Q5: slope with a slope ratio of $1: 0.75$ supported by a $370 \mathrm{~mm}$ wide geobag retaining wall.

of settlement caused by the previous level of load, and a penetrating deep crack will be generated in the slope) as the applied vertical pressure remained unchanged or decreased. The loading process was ceased, and the test ended when the slope suffered a failure. The vertical loading scheme is shown in Figure 6.

\section{Analysis of Test Results}

The horizontal wall (slope) displacement, slope top settlement, and earth pressure on the retaining wall were measured in five cases (Q1, Q2, Q3, Q4, and Q5). The general Coulomb theory was used to calculate the earth pressures on the retaining wall, which were then compared with the measured values.

\subsection{Analysis of Slope Deformation in Different Cases with a Slope Ratio of $1: 0.5$}

3.1.1. Analysis of Slope Top Settlement. At the beginning of loading, the soil was compacted, and the slope top settled with a significant trend of increase in the amount of settlement. As loading continued, the slope top continued to settle with a gradually decreased increase in the amount of settlement due to the compact soil. Constrained by the two sides of the test tank, the slope soil began to press against the retaining wall under the action of the earth pressure, and a small crack appeared in the upper part of the slope. As the load was increased, the crack continued to extend and widen and finally developed into a penetrating crack. The crack in the slope is shown in the area marked with a yellow ellipse in 


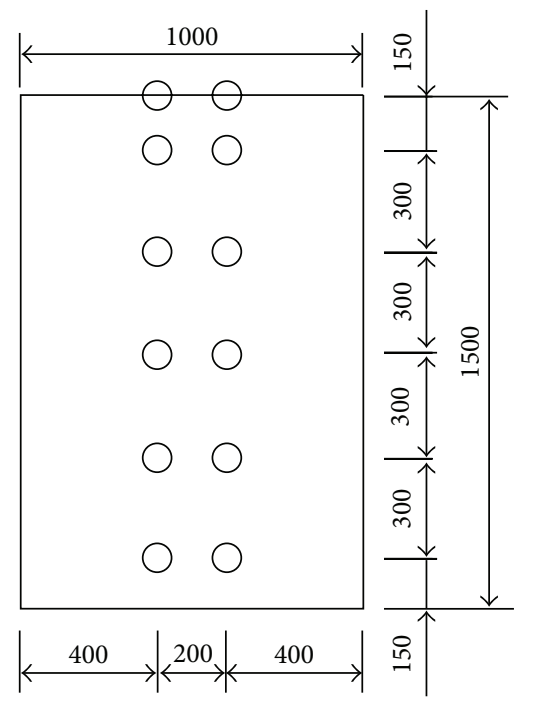

(a) Dial indicators on the wall

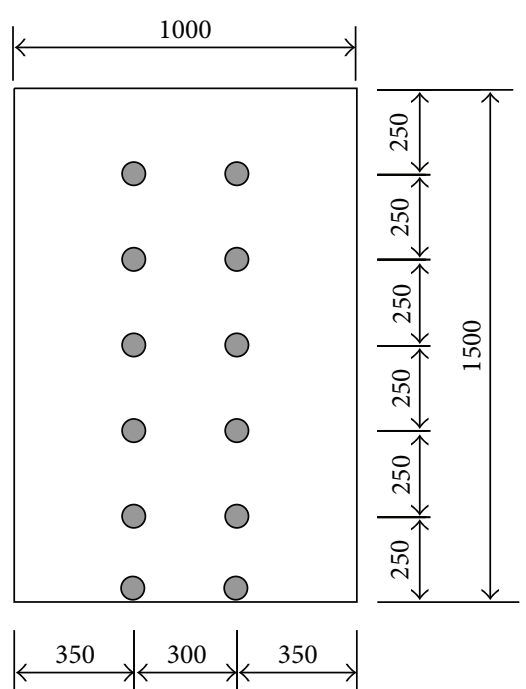

(b) Earth pressure cells on the slope

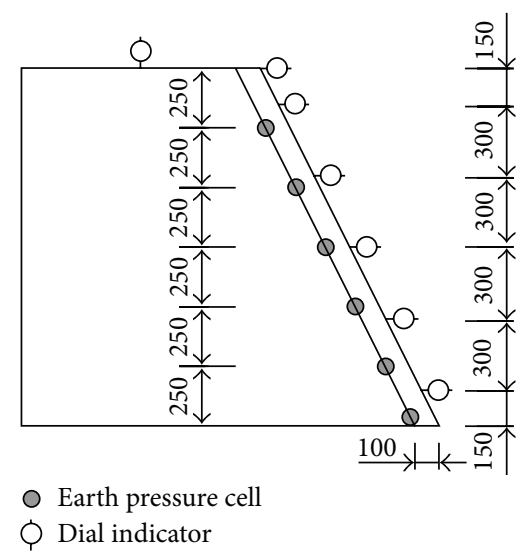

(c) Profile

FIGURE 5: Placement of measuring elements (unit: mm).

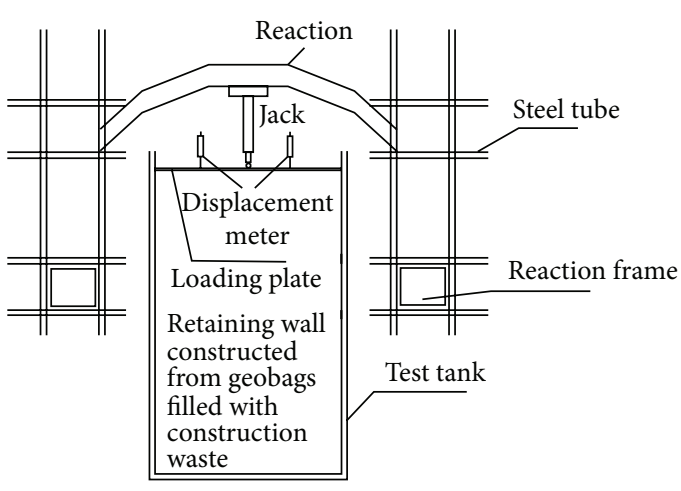

(a) Schematic diagram

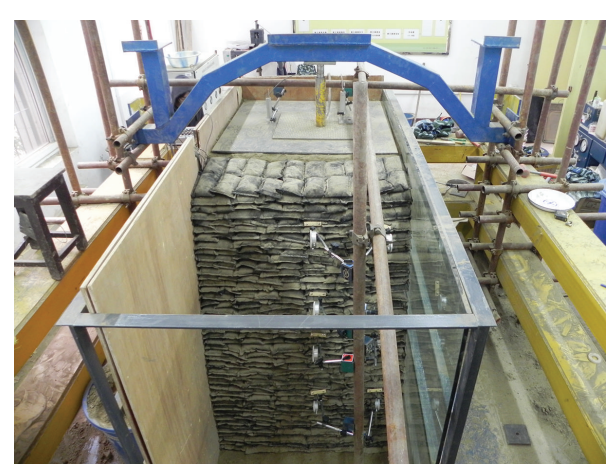

(b) Realistic details

FIGURE 6: Vertical loading system. 


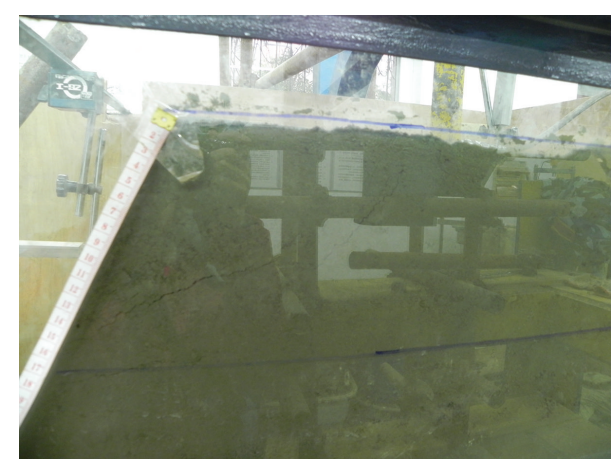

(a) Q1: slope without reinforcement

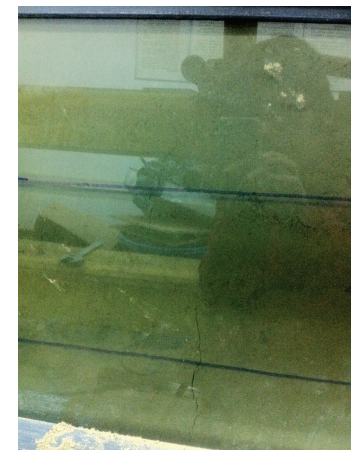

(b) Q2: slope supported by a $370 \mathrm{~mm}$ wide retaining wall constructed from geobags

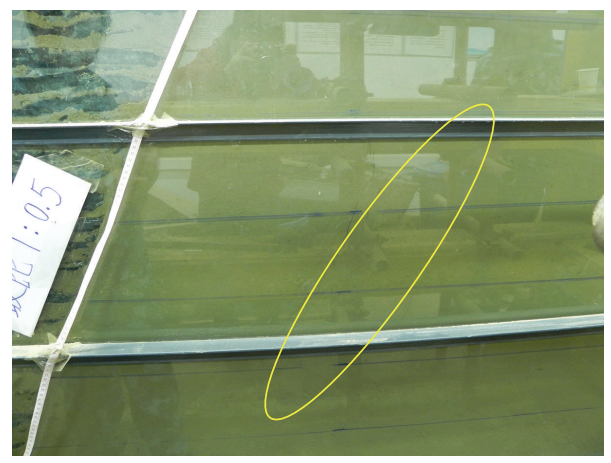

(c) Q3: slope supported by a $570 \mathrm{~mm}$ wide geobag retaining wall

FIGURE 7: Crack distributions in the slopes.

Figure 7, with a length ranging between $300 \mathrm{~mm}$ and $600 \mathrm{~mm}$ and a width ranging between $1 \mathrm{~mm}$ and $3 \mathrm{~mm}$.

With the same slope ratio, the failure loads of the tops of the slope with no support, the slope without reinforcement supported by a $370 \mathrm{~mm}$ wide geobag retaining wall, and the slope supported by a $570 \mathrm{~mm}$ wide geobag retaining wall were found to be $24 \mathrm{kPa}, 45 \mathrm{kPa}$, and $54 \mathrm{kPa}$, respectively, when the slope soil suffered a failure due to a penetrating crack.

The relationship between the uniform load applied to the slope top and the settlement of the slope top in cases Q1, Q2, and Q3 from the beginning of loading to the end of loading when the slope soil suffered a failure is shown in Figure 8. Compared to the top of the slope without reinforcement, the tops of the slopes supported by a geobag retaining wall had a much larger failure load and underwent a much smaller amount of settlement under the same load. The wider the geobag retaining wall was, the larger ultimate load the slope top could bear.

3.1.2. Analysis of Horizontal Wall (Slope) Displacements. The horizontal displacements of the slope without reinforcement were distributed over the slope height as shown in Figure 9. The horizontal displacements of the slope without reinforcement from the bottom to the top of the slope first increased and then decreased. The horizontal displacements of the

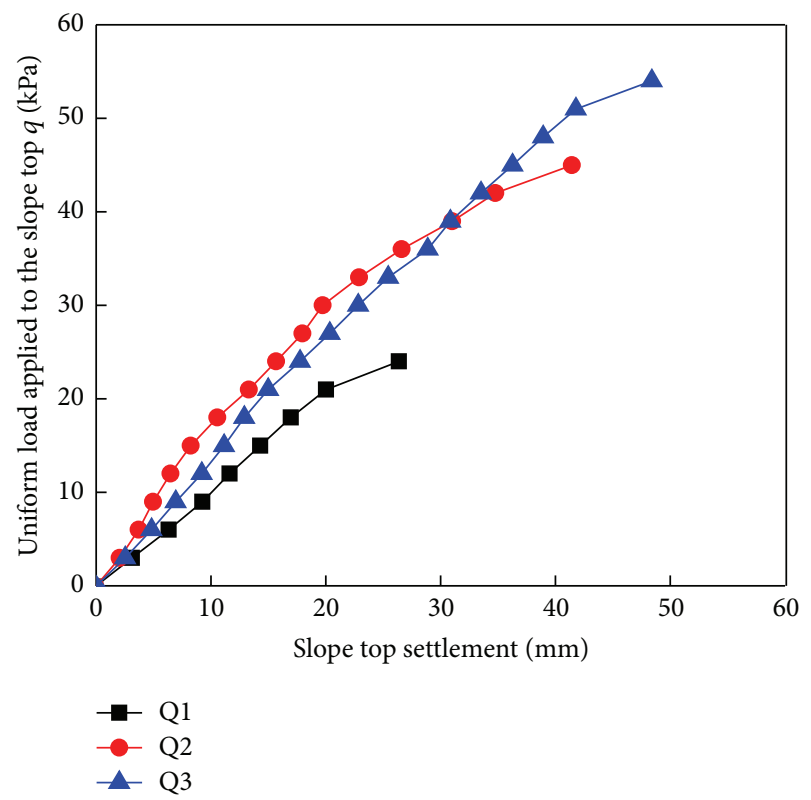

FIGURE 8: Relationship between the uniform load applied to the slope top and its settlement in cases Q1, Q2, and Q3.

retaining walls were distributed over the wall height as shown in Figures 10 and 11. 


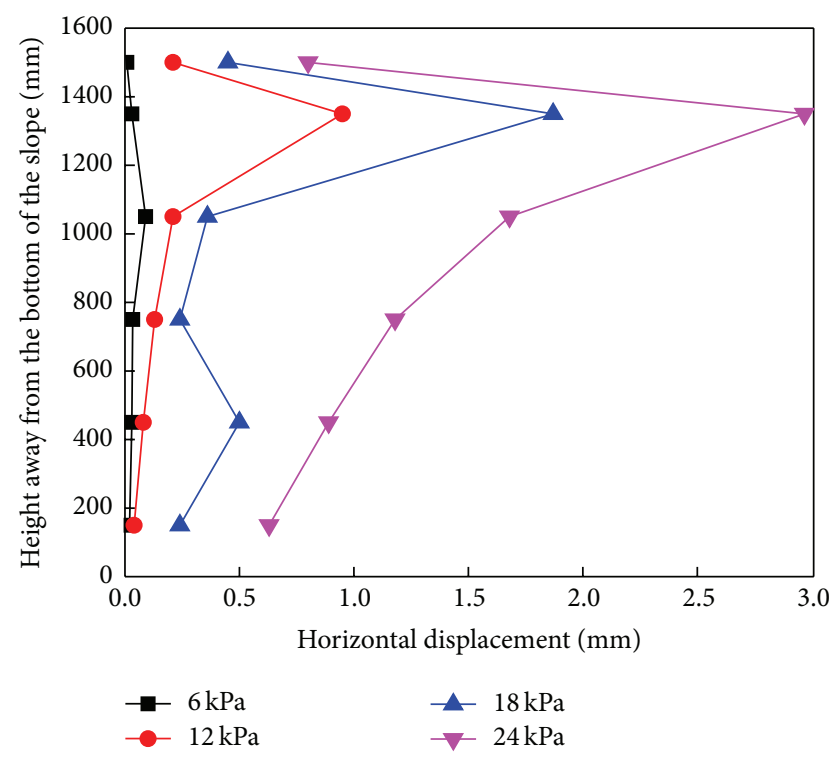

FIGURE 9: Distributions of horizontal slope displacements from the bottom to the top of the slope in case Q1.

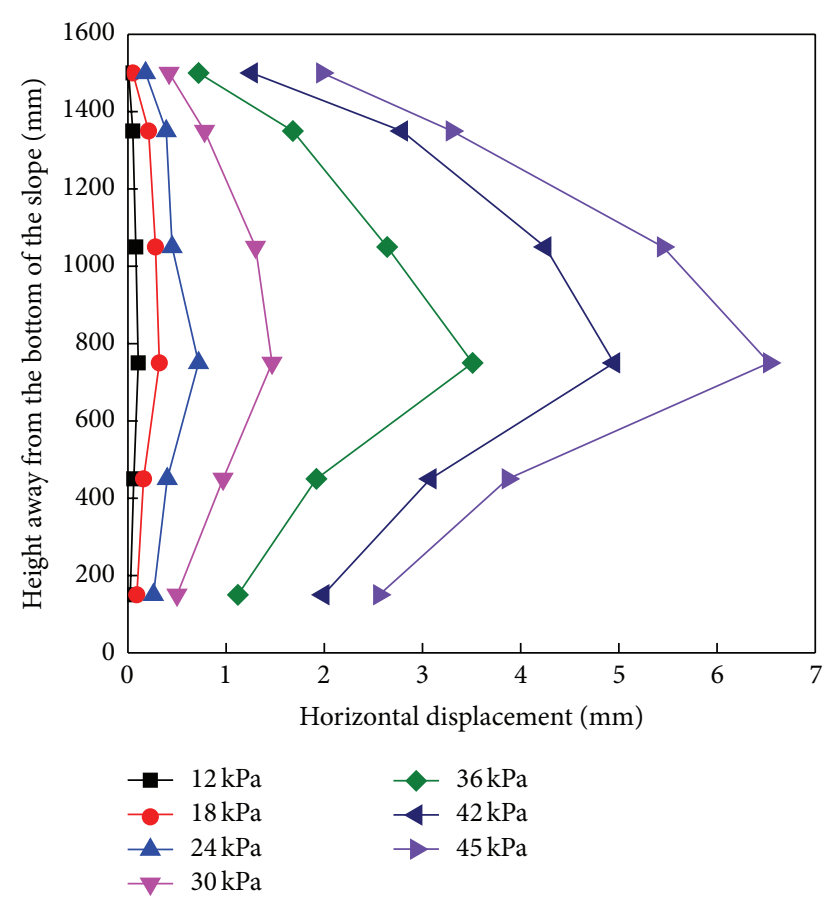

FIGURE 10: Distributions of horizontal wall displacements from the bottom to the top of the wall in case Q2.

A retaining wall constructed from geobags is different from a rigid gravity retaining wall which moves as a whole under the action of a lateral earth pressure. Because the geobag retaining wall is flexible, the geobags in the upper part of the retaining wall deform as the earth pressure on the wall increases, and the horizontal displacements of the wall increase gradually as the earth pressure on the wall develops. Due to the relatively large weight of the geobags in the upper part of the retaining wall, the geobags in the lower

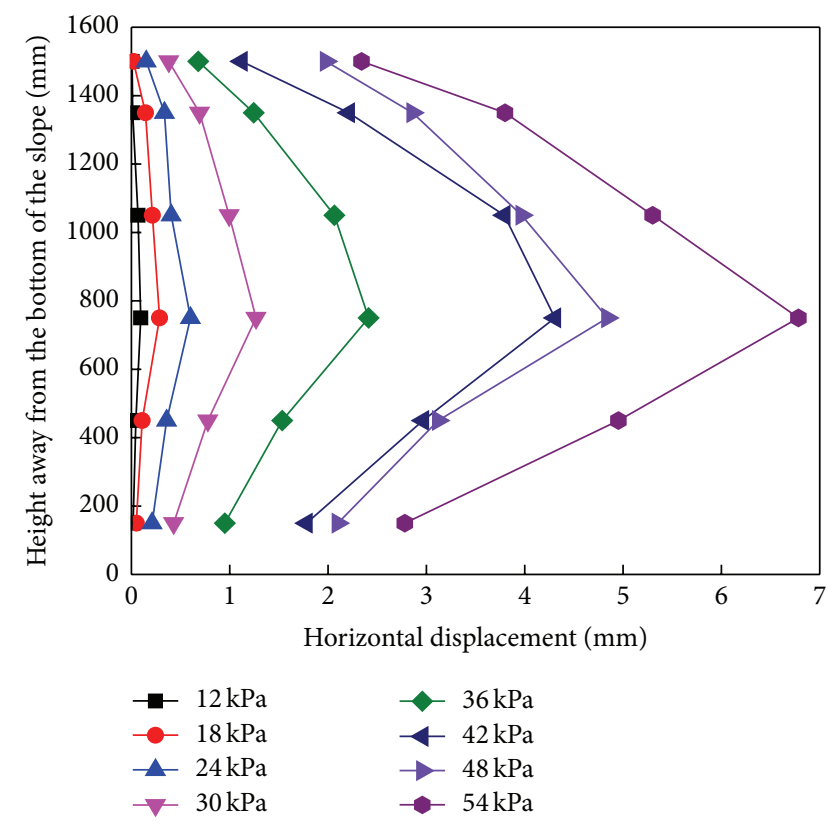

FIGURE 11: Distributions of horizontal wall displacements from the bottom to the top of the wall in case Q3.

part of the retaining wall produce a greater strength, smaller flexible deformation, and smaller horizontal displacement when constrained by the bottom of the slope, from the top to the bottom of the retaining wall.

Therefore, the horizontal displacements of the retaining walls constructed from geobags were distributed in a drum shape, namely, first increased and then decreased from the bottom to the top of the wall. The greatest horizontal displacements occurred about 1/3 1/2 of the wall height away from the bottom of the wall. The wider the retaining walls constructed from geobags were, the smaller the horizontal displacements of the same wall height were.

3.1.3. Analysis of Earth Pressures on the Retaining Walls. The earth pressures on the retaining walls were distributed from the bottom to the top of the wall as shown in Figure 12. The earth pressures on the retaining walls constructed from geobags filled with construction waste were distributed not in a triangular shape but in a drum shape. The measured and calculated values of the earth pressures were distributed linearly over the upper $2 / 3$ of the wall height with insignificant differences. However, the earth pressures showed a turn at $1 / 3$ of the wall height. As a result, the greatest earth pressures occurred not at the bottom of the wall but at about $1 / 3$ of the wall height (Figure 12).

The ultimate loads that the slope tops could bear and the greatest horizontal wall displacements under the same load in various cases were summarized in Table 4 in order to better compare the load bearing characteristics of the slopes in various cases. The greatest horizontal wall displacements under a uniform load of $24 \mathrm{kPa}$, which was the ultimate load that the slope top in case Q1 could bear, were compared. 
TABLE 4: Comparison of the slopes in different cases with a slope ratio of $1: 0.5$.

\begin{tabular}{|c|c|c|c|}
\hline Name & Q1 & Q2 & Q3 \\
\hline Ultimate load that the slope top could bear $/ \mathrm{kPa}$ & 24 & 45 & 54 \\
\hline Greatest horizontal wall displacement (under a load of $24 \mathrm{kPa}$ ) $/ \mathrm{mm}$ & 2.9 & 0.72 & 0.6 \\
\hline
\end{tabular}

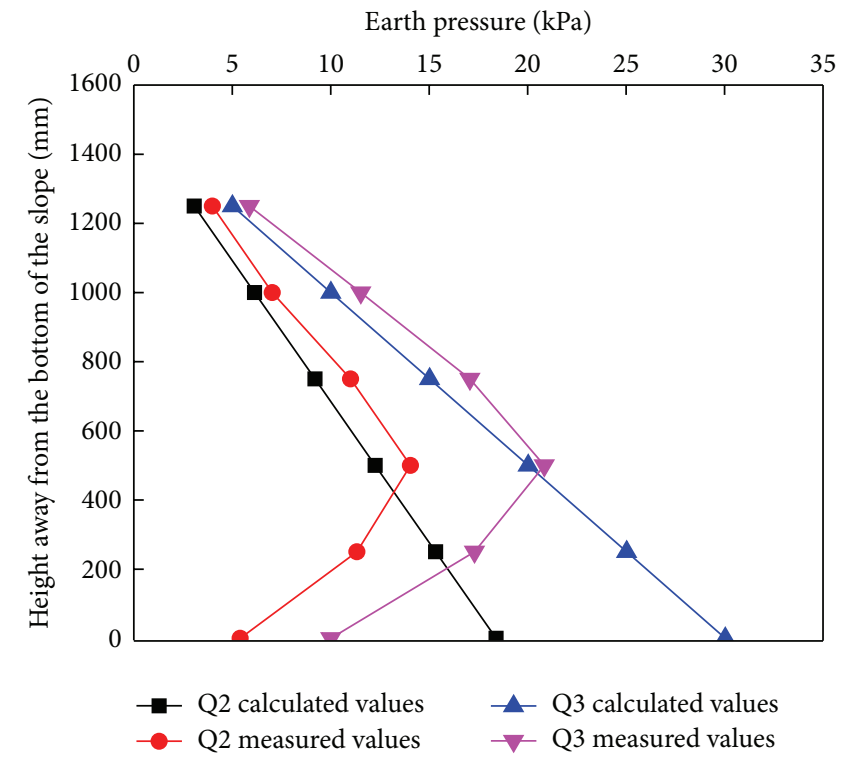

FIGURE 12: Distributions of earth pressures on the retaining walls.

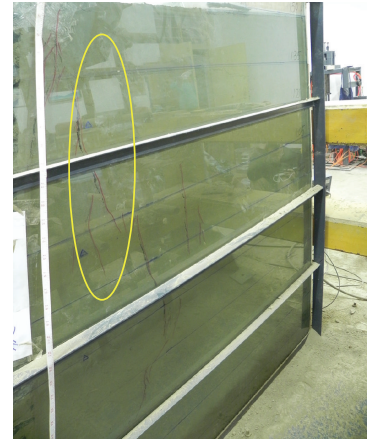

(a) Q4: slope with a slope ratio of $1: 0.25$ supported by geobags

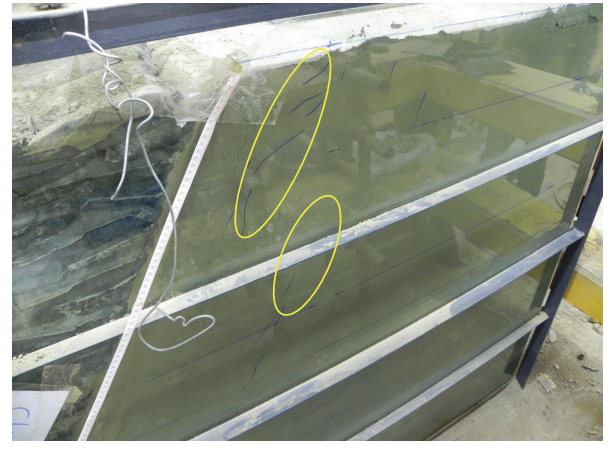

(b) Q5: slope with a slope ratio of 1:0.75 supported by geobags

FIGURE 13: Crack distributions in the slopes with different slope ratios.

The ultimate loads that the slope tops in cases Q2 and Q3 could bear were $87.5 \%$ and $125 \%$, respectively, higher than that of the slope top in case Q1 could bear. The greatest horizontal wall displacements in cases Q2 and Q3 were 75.2\% and 79.4\%, respectively, lower than that in case Q1 under the same uniform load of $24 \mathrm{kPa}$.

\subsection{Analysis of Slope Deformation in Different Cases with a} Retaining Wall Width of $370 \mathrm{~mm}$. The slope top settlements and the distribution characteristics of the horizontal wall displacements and earth pressures on the retaining walls in cases Q2, Q4, and Q5 were compared.
3.2.1. Analysis of Slope Top Settlements. Figure 13 shows the crack distributions in the slopes with different slope ratios (the crack distribution in the slope in case Q2 is shown in Figure 7(b)) when the uniform load applied to the slope tops reached the ultimate load, as marked with a yellow ellipse. The cracks in the slopes were found to range between $300 \mathrm{~mm}$ and $1000 \mathrm{~mm}$ in length and $1 \mathrm{~mm}$ and $4 \mathrm{~mm}$ in width.

Figure 14 shows the relationship between the uniform load applied to the slope tops and their settlement from the beginning of loading to the finish of loading when the slopes suffered a failure. The failure loads of the tops of the slopes with slope ratios of $1: 0.25,1: 0.5$, and $1: 0.75$ supported by 


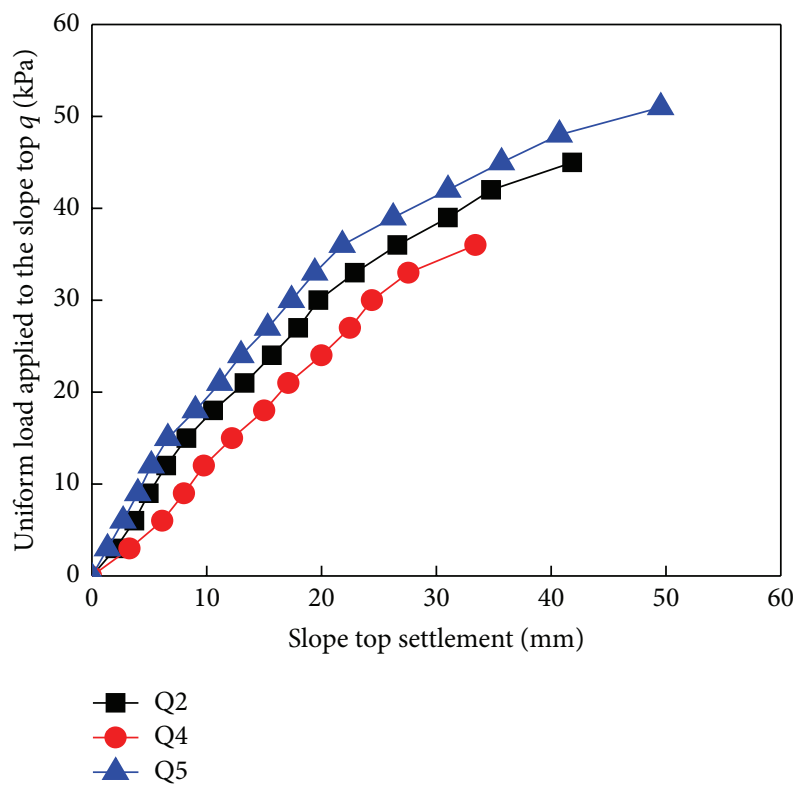

FIGURE 14: Relationship between the uniform load applied to the slope top and its settlement in cases Q2, Q4, and Q5.

the retaining walls constructed from geobags and having the same width were $36 \mathrm{kPa}, 45 \mathrm{kPa}$, and $51 \mathrm{kPa}$, respectively, when the slopes suffered a failure due to a penetrating crack in the slope soil. Compared to the top of the slope supported by a retaining wall, the top of the slope with a smaller slope ratio supported by a retaining wall with the same width had a higher failure load. The top of the slope with a greater slope ratio underwent a larger amount of vertical settlement when the same load was applied to the slope tops.

3.2.2. Analysis of Horizontal Wall Displacements. The horizontal wall displacements were distributed over the wall height as shown in Figures 15 and 16. The wall supporting a steeper slope produced a greater vertical displacement at the same height away from the bottom of the wall when the same load was applied to the slope tops. The greatest horizontal wall displacements occurred 1/3 1/2 of the wall height away from the bottom of the wall.

3.2.3. Analysis of Earth Pressures on the Retaining Walls. The earth pressures on the retaining walls in cases Q2, Q4, and Q5 were distributed over the wall height as shown in Figure 17. The earth pressures on the retaining walls constructed from geobags filled with construction waste first increased to their maximum and then decreased gradually from the bottom to the top of the wall, with their smallest values occurring at the tops of the retaining walls, and decreased as the slope ratio increased.

The ultimate loads that the slope tops could bear and the greatest horizontal wall displacements under the same load in various cases were summarized in Table 5 in order to better compare the load bearing characteristics of the slopes in various cases. The greatest horizontal wall displacements

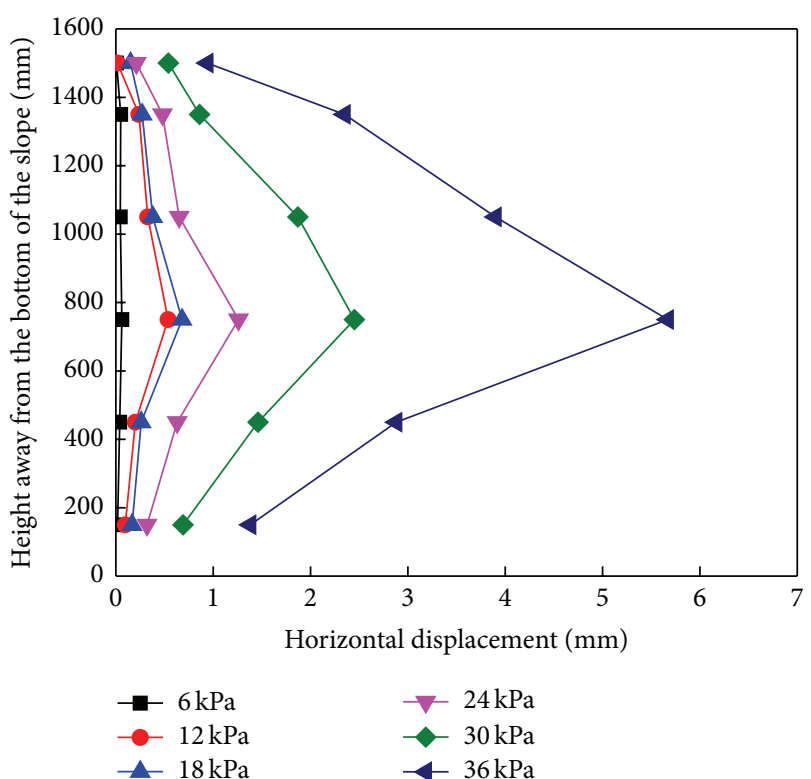

FIGURE 15: Distributions of horizontal wall displacements over the wall height in case Q4.

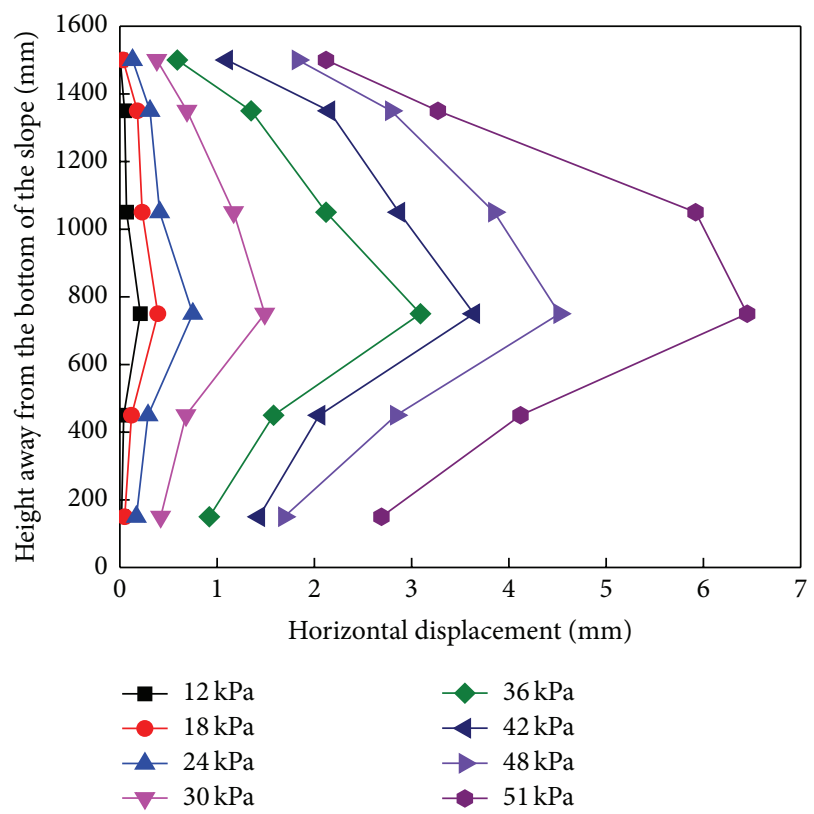

FIGURE 16: Distributions of horizontal wall displacements over the wall height in case Q5.

under a load of $36 \mathrm{kPa}$, which was the ultimate load that the slope top in case Q4 could bear, were compared.

The ultimate loads that the slope tops in cases Q2 and Q5 could bear were $25 \%$ and $125 \%$, respectively, higher than that of the slope top in case Q4 could bear. The greatest horizontal wall displacements in cases Q2 and Q5 were 45.3\% and 49.7\%, respectively, lower than that in case $\mathrm{Q} 4$ when the same load of $36 \mathrm{kPa}$ was applied to the slope tops. 
TABLE 5: Comparison of slopes in different cases with a retaining wall width of $370 \mathrm{~mm}$.

\begin{tabular}{|c|c|c|c|}
\hline Name & Q2 & Q4 & Q5 \\
\hline Ultimate load that the slope top could bear $(\mathrm{kPa})$ & 45 & 36 & 51 \\
\hline Greatest horizontal wall displacement under a load of $36 \mathrm{kPa}(\mathrm{mm})$ & 3.51 & 5.67 & 3.15 \\
\hline
\end{tabular}

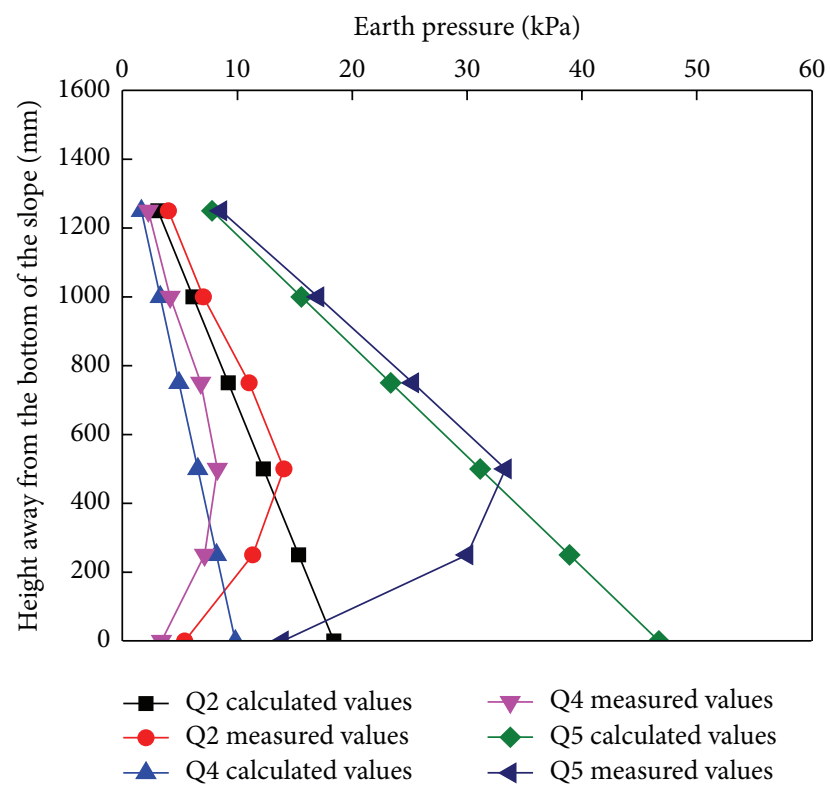

FIGURE 17: Distributions of soil pressures on the retaining walls.

3.3. Analysis of Failure Modes. The crack distributions in the slopes in the five cases shown in Figures 7 and 13 were recorded, and the slip surfaces formed by the through cracks were drawn in Figure 18 in order to study the failure modes of the soil behind the retaining walls.

3.3.1. Failure of the Slope without Reinforcements. As shown in Figure 18(a), the slope with no support suffered a local failure near the slope shoulder with an arc-shaped slip surface (as shown in Figure 7), which belonged to sliding. The front edge of the slip face was $1305 \mathrm{~mm}$ away from the bottom of the wall.

3.3.2. Failures of the Slopes Supported by the Retaining Walls Constructed from Geobags. According to Figure 18, the slip surfaces of the failures of the soil behind the retaining walls constructed from geobags showed different modes.

In Figure 18(c), the slip surface of the soil behind the retaining wall in case Q2 formed an arc-broken-line shape, with its front edge $573 \mathrm{~mm}$ away from the bottom of the wall. In Figure 18(d), the slip surface of the soil behind the retaining wall in case Q3 formed an arc-broken-line shape, with its front edge $526 \mathrm{~mm}$ away from the bottom of the wall. The failures of the soil in cases Q2 and Q3 were displayed as sliding and toppling and dominated by sliding.

In Figure 18(e), the slip surface of the soil behind the retaining wall in case Q4 formed a broken-line shape, with its front edge $634 \mathrm{~mm}$ away from the bottom of the wall, and the failure of the soil was displayed as toppling and sliding and dominated by toppling.

The slip surfaces of the slope soil in various cases were similar in that their front edges were all located 1/3 1/2 of the wall height away from the bottom of the wall, though at different heights.

The soil at the front edge of the slip surfaces had the strongest trend to slide forward, produced the greatest horizontal displacement, and applied the greatest force to the retaining wall. The front edges of the slip surfaces were all located about $1 / 3$ of the wall height away from the bottom of the wall. This explained why the greatest horizontal displacements in the various cases all occurred about 1/3 1/2 of the wall height away from the bottom of the wall as reflected by Figures 10, 11, 15, and 16 and why the greatest earth pressures in the various cases occurred near this location as reflected by Figures 12 and 17.

Therefore, the range of about $1 / 3 \sim 1 / 2$ of the wall height away from the bottom of the wall is the weak part of retaining walls constructed from geobags filled with construction waste which should be reinforced during the process of design and construction.

\section{Conclusions}

In this paper, model tests on the retaining walls constructed from geobags filled with construction waste were conducted, and the results suggest the following conclusions can be drawn:

(1) The ultimate loads that the slope tops in cases Q2 and Q3 could bear were $87.5 \% \sim 125 \%$ higher than that of the slope top in case Q1. The greatest horizontal wall displacements in cases Q2 and Q3 were 75.2\% 79.4\% lower than that in case Q1 under the same load of $24 \mathrm{kPa}$, and the retaining walls constructed from geobags filled with construction waste were found to provide significant supporting effects to the slopes.

(2) The ultimate loads that the slope tops in cases Q2 and Q5 could bear were 25\% 125\% higher than that of the slope top in case Q4. The greatest horizontal wall displacements in cases Q2 and Q5 were 45.3\% 49.7\% lower than that in case Q4 under the same load of $36 \mathrm{kPa}$.

(3) The horizontal displacements of the retaining walls constructed from geobags were distributed in a drum shape, with the greatest horizontal displacement occurring about $1 / 3 \sim 1 / 2$ of the wall height away from the bottom of the wall. The earth pressures on the 


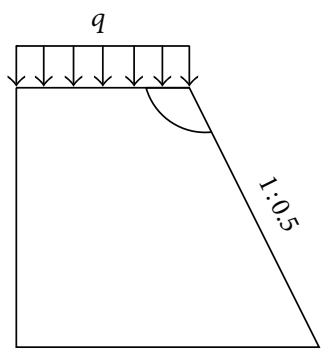

(a) Q1

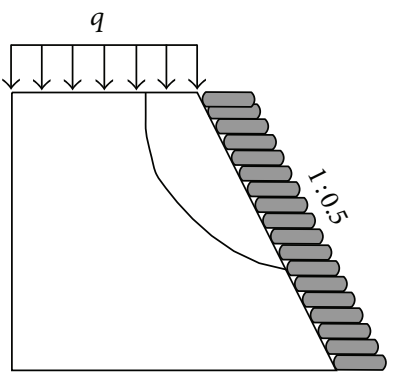

(c) Q2

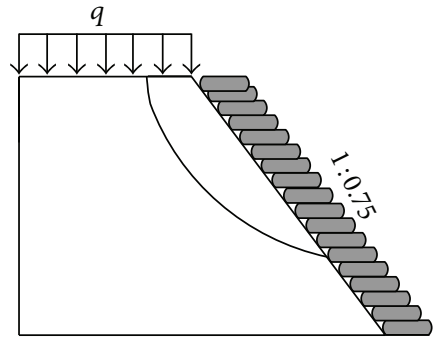

(b) Q5

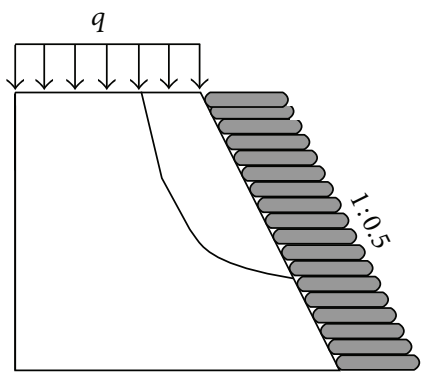

(d) Q3

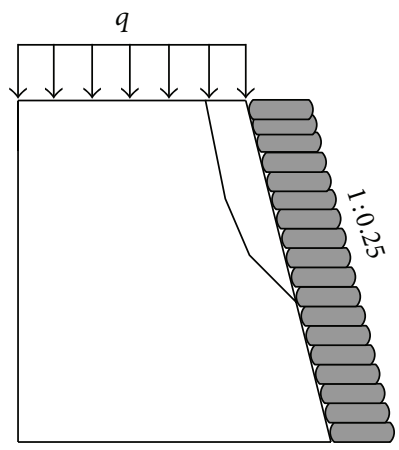

(e) Q4

FIGURE 18: Slip surfaces of slope soil in different cases.

retaining walls constructed from geobags filled with construction waste were distributed nonlinearly, with the greatest earth pressures occurring about $1 / 3$ of the wall height away from the bottom of the wall.

(4) As the slope ratio increased, the failure of the slope soil supported by the geobag retaining wall filled with construction waste changed from sliding to sliding toppling (dominated by sliding) and then to toppling sliding (dominated by toppling). The slip surfaces of the soil supported by the retaining wall changed from an arch shape to a broken-line shape, and their front edges were all located about 1/3 1/2 of wall height away from the bottom.

(5) The range of about $1 / 3 \sim 1 / 2$ of the wall height away from the bottom of the wall is the weak part of retaining walls constructed from geobags filled with construction which should be reinforced during the process of design and construction.

\section{Competing Interests}

The authors declare that they have no competing interests.

\section{Acknowledgments}

The authors gratefully acknowledge the financial support of this work, which was provided by the National Natural Science Foundation of China (nos. 41172260 and 51108393), the Research Foundation of Education Bureau of Sichuan Province (16ZA0139), and the Doctoral Fund of Southwest University of Science and Technology (15zx7152).

\section{References}

[1] B. A. G. Bossink and H. J. H. Brouwers, "Construction waste: quantification and source evaluation," Journal of Construction Engineering and Management, vol. 122, no. 1, pp. 55-60, 1996.

[2] R. Korkut, E. J. Martinez, R. Morales, R. Ettema, and B. Barkdoll, "Geobag performance as scour countermeasure for 
bridge abutments," Journal of Hydraulic Engineering, vol. 133, no. 4, pp. 431-439, 2007.

[3] S. Yan and J. Chu, "Geo-bag method for levee construction and rehabilitation," in Proceedings of the GeoCongress, pp. 694-699, New Orleans, La, USA, March 2008.

[4] H. Matsuoka and S. Liu, A New Earth Reinforcement Method Using Soilbags, A A Balkema, Rotterdam, The Netherlands; Taylor \& Francis, London, UK, 2005.

[5] S. J. Restall, L. A. Jackson, G. Heerten, and W. P. Hornsey, "Case studies showing the growth and development of geotextile sand containers: an Australian perspective," Geotextiles and Geomembranes, vol. 20, no. 5, pp. 321-342, 2002.

[6] G. Li, Y. Chen, and X. Tang, Geosynthetics in Civil and Environmental Engineering, Springer, New York, NY, USA, 2009.

[7] A. Akter, G. Pender, G. Wright, and M. Crapper, "Performance of a geobag revetment. I: quasi-physical modeling," Journal of Hydraulic Engineering, vol. 139, no. 8, pp. 865-876, 2013.

[8] Y. Ansari, R. Merifield, H. Yamamoto, and D. Sheng, "Numerical analysis of soilbags under compression and cyclic shear," Computers and Geotechnics, vol. 38, no. 5, pp. 659-668, 2011.

[9] A. Akter, M. Crapper, G. Pender, G. Wright, and W. Wong, "Performance of a geobag revetment. ii: numerical modeling," Journal of Hydraulic Engineering, vol. 139, no. 8, pp. 877-885, 2013.

[10] H. Oumeraci and A. Kortenhaus, "Core made of geotextile sand containers for rubble mound breakwaters and seawalls: effect on armour stability and hydraulic performance," Ocean Engineering, vol. 38, no. 1, pp. 159-170, 2011.

[11] A. Akter, G. Pender, G. Wright, and M. Crapper, "Predicting the hydrodynamic forces on geobag revetments," Journal of Flood Risk Management, vol. 4, no. 4, pp. 328-338, 2011.

[12] A. Rao, K. N. Jha, and S. Misra, "Use of aggregates from recycled construction and demolition waste in concrete," Resources, Conservation and Recycling, vol. 50, no. 1, pp. 71-81, 2007.

[13] H. Birgisdóttir, G. Bhander, M. Z. Hauschild, and T. H. Christensen, "Life cycle assessment of disposal of residues from municipal solid waste incineration: recycling of bottom ash in road construction or landfilling in Denmark evaluated in the ROAD-RES model," Waste Management, vol. 27, no. 8, pp. S75S84, 2007.

[14] O. Jenck, D. Dias, and R. Kastner, "Discrete element modelling of a granular platform supported by piles in soft soil-validation on a small scale model test and comparison to a numerical analysis in a continuum," Computers and Geotechnics, vol. 36, no. 6, pp. 917-927, 2009.

[15] Industry Standard of the People's Republic of China, Specification of Soil Test(S1237-1999), Liaoning Nationality Publishing House, Shenyang, China, 1999 (Chinese). 

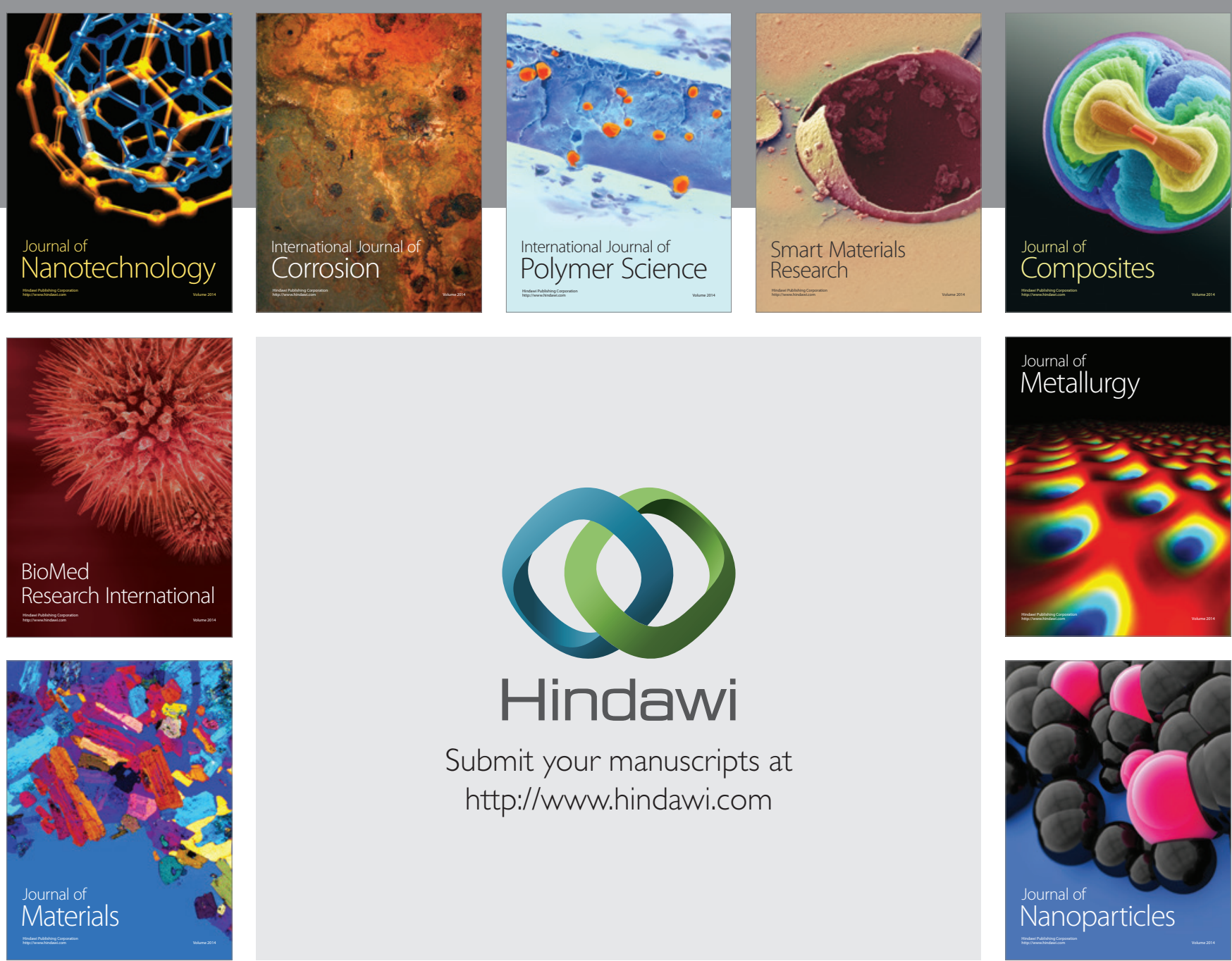

\section{Hindawi}

Submit your manuscripts at

http://www.hindawi.com

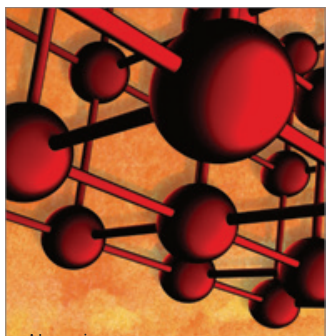

Materials Science and Engineering
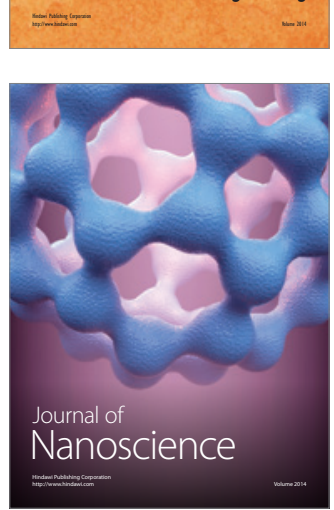
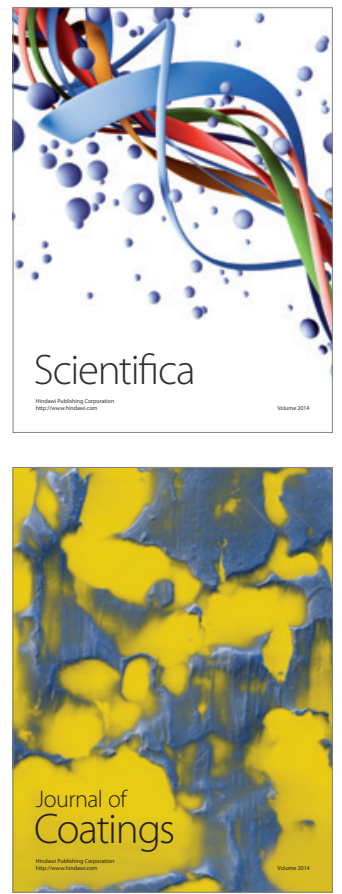
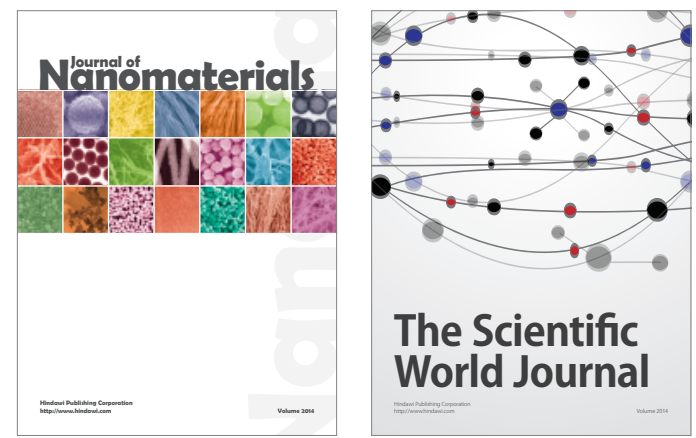

The Scientific World Journal
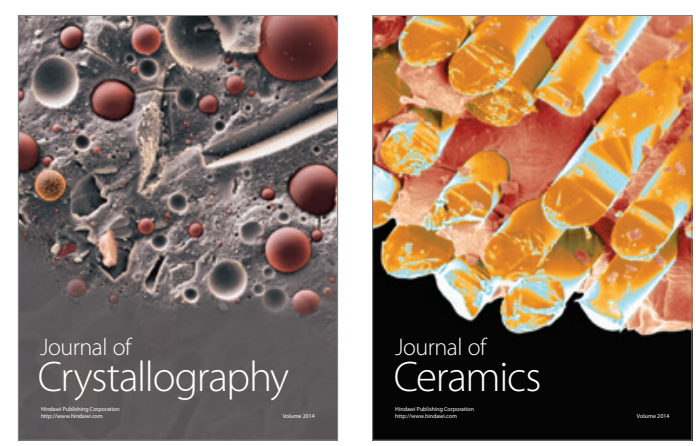
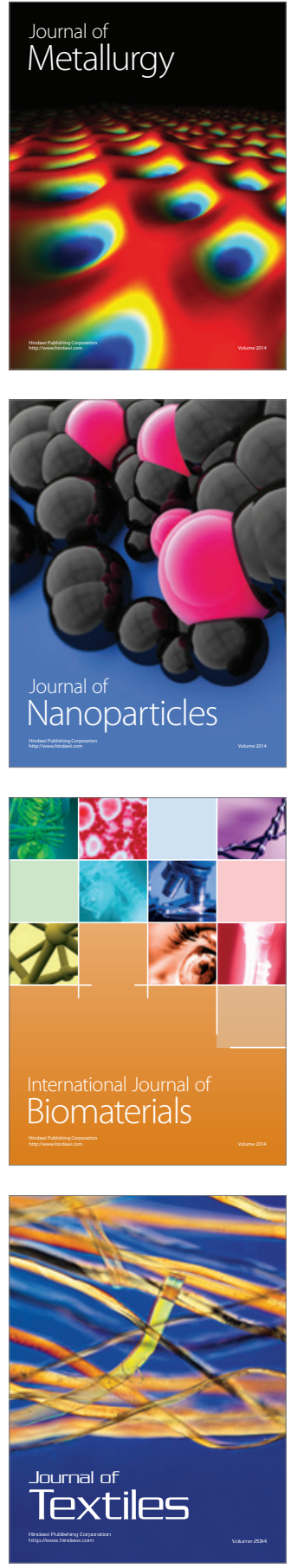